\title{
Towards integrating built heritage resources in urban development through spatial planning
}

\author{
K. Puren \& T. Jordaan \\ Subject Group Urban and Regional Planning, \\ North-West University, South Africa
}

\begin{abstract}
Cities and towns in developing countries increasingly face the challenge of balancing urban conservation and development due to rapid urbanisation and development pressure. Modernism, that resulted in spatially fragmented towns and cities worldwide, together with urban development and urban conservation in South Africa regulated by separate legislation, place built environment heritage resources at risk of destruction because they are being treated as isolated objects, instead of an intrinsic part of the contemporary urban fabric. This paper is based on a research project conducted for the City of Matlosana in the North-West Province, South Africa that aimed to develop proposals to integrate urban conservation and urban development in Klerksdorp, the second oldest city in the old Transvaal Republic (today divided into the North West, Gauteng, Mpumalanga and Limpopo Provinces). The process followed a qualitative participatory approach. Data was collected from archival records, a field survey and interviews with participants and other stakeholders. The findings revealed spatial fragmentation of built heritage distribution and non-alignment of planning and management processes with regard to urban conservation and development decision-making. A three-tier framework for integrating built heritage in urban development is proposed that consists of: (i) physical/spatial integration through physical planning and design, (ii) integration of urban conservation and urban development through local policy/legislation and (iii) procedural integration in terms of decision-making. A paradigm shift in urban conservation is suggested from preserving heritage resources as isolated objects towards a more proactive integration into the contemporary uses and future development of cities. Keywords: urban conservation, urban development, spatial planning.
\end{abstract}




\section{Contextualisation of the study: urban conservation and urban development}

The United Nations [1] projected that by 2012 three billion of the world's population of seven billion would be urbanised. By 2030 the number of urban residents will have risen to more than $60 \%$ of the world population. Such rapid urbanisation means increasing development pressure in urban areas to provide housing, infrastructure and rising living standards for residents [2, 3]. Historical places, and subsequently built heritage resources as prominent human cultural expression, are especially at risk in responding to contemporary commercial forces. If built heritage resources are damaged or destroyed, the loss of value is irreversible [4]. Increasing development pressure therefore highlights the urgency of considering how urban conservation and urban development should be integrated [3].

Conservation of heritage resources is often linked with sustainable development [5] and increased economic investment [6, 7]. However, preservation costs of built heritage resources are high [8], as this must be done using skilled labour and scarce or costly building materials [4]. Integrating built heritage into the existing urban fabric and future development of cities in such a way that its contemporary use can support its continued existence may be a step in the direction of a more sustainable approach to urban conservation compared to previous preservationist approaches and more appropriate for developing countries.

Associating a contemporary use with an existing built heritage, referred to as 'adaptive reuse' or 'balanced integration' [8] of built heritage provides an alternative to the 'preservation' paradigm, where the emphasis is on protecting built heritage from harm or destruction in an isolated manner as by maintaining its original form and function [9]. This change in direction concerning the integration of built heritage into urban development as an integral part of the urban fabric, instead of an object preserved apart from it, seems to be an outcome of underlying paradigm shifts in global society, especially in terms of the move from modernism to post-modernism, and with it acceptance of plurality in ways of viewing the world.

Important underlying differences between modernist and post-modernist perceptions of heritage lie in how perceptions of time and the continuous transformation of society through time are embraced $[8,10]$. The Western way of thought is often associated with a linear sense of time $[8,11]$ in which a definite break can be perceived between past, present and future, which easily relates either to irreversible damage to built heritage, or to a preservationist approach in heritage planning where built heritage are preserved in isolation $[8,9]$. The Eastern and African way of thought reflects a more cyclical perception of time in which past, present and future is viewed as integrated $[11,12]$. This modernist and postmodernist dichotomy also influenced how built heritage is treated in urban planning. Modernism clearly signalled a break from the past in urban planning, while post modernism tries to re-establish ties with the past [13]. For many authors [14-18] the idea of heritage is present-centred and the study of heritage is rather what is selected from the past to be used in the present [15] than preserving the 
past per se. Heritage in this regard is increasingly defined in terms of contemporary uses of the past, as well as present needs, such as tourism to meet economic needs. Integrating conservation of built heritage resources into urban development therefore gives built heritage a contemporary societal role [19]. However, the post-modern interpretation of the heritage/adaptive reuse/balanced integration is deeply seated in the acceptance of multiplicity: multiple pasts, identities and cultures [15]. This acceptance is an uneasy one, because multiplicity can cause contestation and dissonance over heritage, its meanings and how it should be represented, if at all [15].

In South Africa where a dichotomy of Western and African thought exists, integrating built heritage into urban development is a contentious issue confronted with numerous challenges. One of these challenges relates to South Africa's spatial planning system, influenced by modern planning systems that contributed to a large extent to the current segregated urban form, culminating in the easy destruction or isolation of historical urban areas in the name of 'reconstruction' and development [20]. Another challenge relates to redefining what built heritage is, as well as its function in a multicultural South African society. This is opposed to a tradition in which only a Western preservationist perception of built heritage was long upheld in policies and legislation [21, 22]. It is especially the first challenge that this article would like to address, as spatial planning policy and legislation guide development.

Planning has the power to shape the built environment and may form a bridge between built heritage resources and development, especially as the adaptive reuse/balanced integration idea is supportive of development where there is need for it [8]. Built heritage conservation has up until now not been fully integrated into development planning and management of towns and cities in South Africa. In some cases, this resulted in built heritage resources being either destroyed or treated as isolated objects, instead of being treated as an intrinsic part of the existing urban fabric. Though various legislation exist that focus on heritage management, like the National Heritage Resources Act (NHRA) [23], the National Environmental Management Act 107 of 1998 (NEMA) [24], and the World Heritage Convention Act 49 of 1999 (WHCA) [25], it is not integrated in the legislation that guide urban development, particularly spatial planning policy and legislation. Yet, the potential for spatial planning to serve as a tool for integrating urban conservation and development seems promising, as reflected in the multidimensional definition of planning as "a dynamic profession that works to improve the welfare of...communities by creating more convenient, equitable, healthful, efficient, and attractive places for present and future generations.... It helps them find the right balance of new development and essential services, environmental protection, and innovative change" [26]. This emphasises spatial planning as something that is complex but adaptive in nature. Spatial planning seems to be a possible tool with the ability to integrate development and conservation of built heritage in a balanced manner.

This paper is based on a research project conducted for the City of Matlosana in the North-West Province, South Africa that aimed to develop broad proposals to integrate urban conservation and urban development in Klerksdorp, a medium 
sized city. Secondary aims of the project included deliverables such as (i) the identification of built heritage resources for future conservation in Klerksdorp; (ii) prioritisation of built heritage to conserve; (iii) an integrated spatial mapping and analysis of Klerksdorp's built heritage and (iv) an analysis of whether and to what extent is urban conservation and urban development integrated in municipal decision-making.

\section{Study area}

According to the North West Provincial Spatial Development Framework [27], it is expected that Klerksdorp will be the second largest city in the province by 2015. Due to high urbanisation rates (the second highest in the North-West province at $84.6 \%)$ Klerksdorp functions as a primary urban node in the province [27]. The city, identified as an area with high economic and investment potential [27] is located on the N12 Treasure Route between Johannesburg and Kimberley (figure 1) and earmarked as a Priority Development Zone of the Treasure Spatial Development Initiative [27]. Klerksdorp is the second oldest city in the old Transvaal Republic (today divided into the North West, Gauteng, Mpumalanga and Limpopo Provinces), as Klerksdorp's first formal settlement was established in 1837 [28]. The city is therefore a rich source of built heritage. This, combined with the provincial government's socio-economic development vision for the municipality, creates conflict between development and conservation, establishing a need for the balanced integration of urban heritage with urban development.

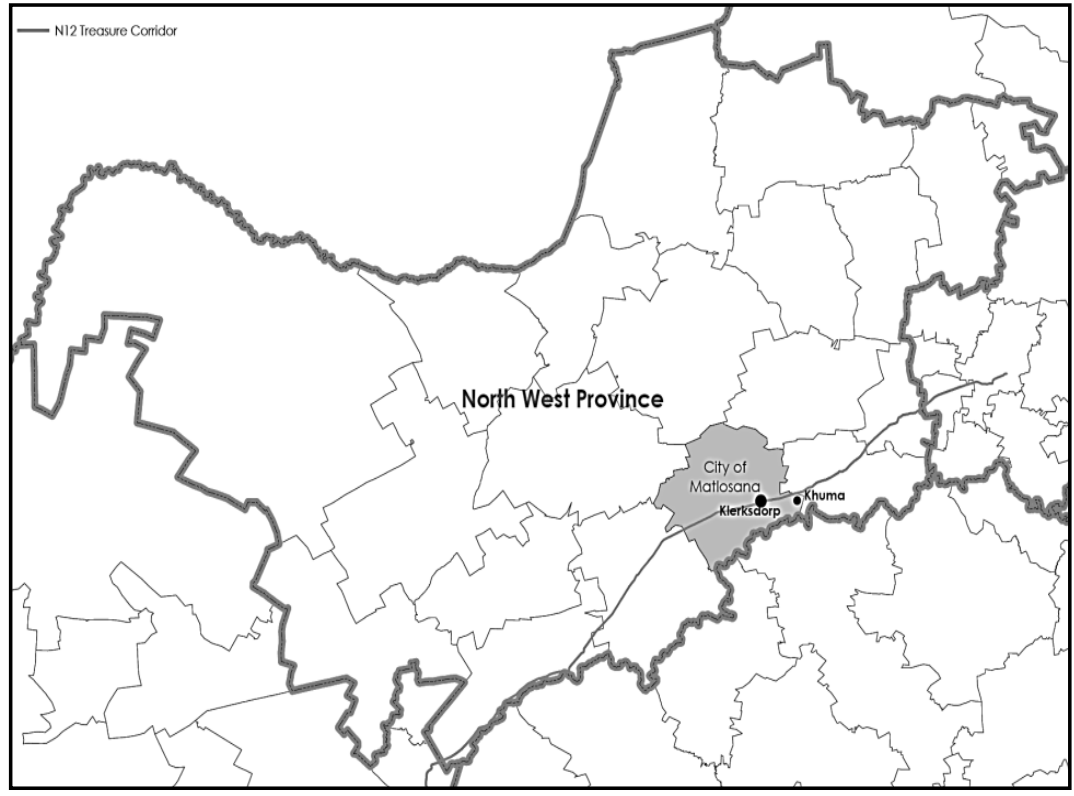

Figure 1: Study area. 


\section{Process followed and methods used}

In order to develop proposals for integrating built heritage and urban development in the City of Matlosana, Klerksdorp, four phases were followed. A brief description of each research phases, its goals and methods used are provided in the following section. The multicultural nature of South African cities required an approach that acknowledged the plurality of heritage, not only the multiple interpretations of what heritage resources means, but also the multiple ways in which these resources can be utilised in urban development [15]. As such, a participatory approach was followed throughout the research project.

Phase one: The goal of this phase was to capture all existing and potential heritage sites to be integrated in the future development of Klerksdorp. This phase of the research firstly entailed the compilation of a preliminary inventory of existing heritage sites/structures from archival records, existing studies and an extensive field survey to document the site/structure in terms of its location, significance, current land use, allowed land uses and architectural and construction details. While data with regard to formally identified Grade I and Grade II built heritage (national and provincial heritage resources) was easy to obtain, sites and structures of local importance (Grade III) were not incorporated in existing documents and needed to be obtained by the inclusion of local citizen's knowledge. Twenty key informants were identified through purposive sampling for the informed opinion and insight they would be able to give about the built heritage in the study area, as well as for their familiarity with the unique historical, socio-cultural and political context in which the research is embedded [29]. Not all of the purposefully identified participants could participate in the research, so additional participants were identified through snowball sampling [30]. The final group of participants included 13 males (aged 46 to 82 years) and seven females (aged 22 to 60). The participants were selected for their previous experience or detailed knowledge of built heritage resources in Klerksdorp. The key informants were given disposable cameras to take photographs over three weeks of what they considered to represent Klerksdorp's heritage. Individual in-depth interviews based on their photographs were conducted with the participants to i) obtain insight into the scope of built heritage resources and their potential for future use, as well as ii) to obtain insight in participant's experiences of how well the conservation of built heritage is managed in the study area. This phase was used to refine the final draft inventory of Klerksdorp's built heritage.

Phase two: The goal of this phase was to obtain input from the public in terms of additional heritage sites/structures to be preserved, as well as to prioritise the existing and potential built heritage in terms of its significance. This participation process included an information page published in the local newspaper for a period of four weeks in a special section that, apart from obtaining data on heritage sites/structures and their priority in terms of conservation, aimed to create awareness of arts and culture in Matlosana Municipality. It asked members of the public to comment and share stories about the preliminary inventory (published in the form of photographs of all existing and newly identified sites/structures). Posters with photographs and a map of existing and potential heritages were 
displayed at three prominent public places, the public library, the municipal offices and the Klerksdorp museum, where members of the public had the opportunity to comment or add additional heritage sites to the list and prioritise heritage sites for conservation. The posters were monitored full time on a daily basis on weekdays and photographed to gather the public's input on the prioritisation of built heritage and listed additions.

Phase three: This phase included an analysis of relevant policies and legislation pertaining urban development and conservation together with conducting semistructured interviews with various participants such as municipal officials, private sector urban planners and representatives of heritage bodies in order to evaluate to what extent urban conservation and urban development is integrated in the study area.

Phase four: During this phase the data from the final heritage inventory were spatially mapped and analysed according to the spatial distribution of the built heritage sites, with the focus on built heritages' connection to the urban envelope and other built heritage in the proximity, as well as spatial patterns that emerged from these.

\section{Integrated findings}

A synopsis of the integrated findings that emerged from the research process followed is briefly outlined in this section.

\subsection{Phases one and two: identification and prioritisation of built heritage resources in Klerksdorp}

An inventory of 55 heritage resources was finalised from existing databases, previous studies, the survey, interviews and public responses. Key informants were a useful method to obtain in-depth insight into the historical context of the study area, details surrounding the various heritage sites and prioritisation of their importance. Also, the photographs used in the interviews prompted discussions and elicited underlying meanings connected to these sites, such as emotional attachment (a sense of belonging and identity), respect for one's own heritage and even feelings of loss and helplessness in preventing injudicious destruction of heritage. The public response included: i) 20 members of the public that handed in the newspaper information page at the museum with their indication of important and less important heritage resources; ii) telephone calls to enquire about the research project and individuals offering their availability to supply information on particular identified heritage sites; iii) three members of the public made appointments with the researchers to share information and stories; and iv) the public responded to the public notice boards on the posters by indicating important and less important sites in Klerksdorp. Altogether twenty-five sites were identified as very important, 10 as important and 16 as less important. In following a participatory process, individuals that shared their stories added valuable insight to the background, scope and context of Klerksdorp's history. 


\subsection{Phase three: integration of urban conservation and urban development}

Urban development and urban conservation in South Africa is regulated by separate legislation. The National Heritage Resources Act (NHRA) [23] serves as the core legislation that regulates heritage resources in South Africa. While this act includes various sections on how spatial planning should respond to and integrate built heritage in urban development, local planning policy in the study area (e.g. the Spatial Development Framework and Land Use Management Scheme) has up until now not yet integrate built heritage in the management of urban development. Furthermore, the interviews conducted confirmed that internal municipal departments (e.g. spatial planning, building control and community services) involved in decision-making with regard to urban conservation and urban development are not aligned. This hindered proactive inclusion of build heritage in urban development as decisions with regard to built heritage (e.g. destruction or change of use) are managed on an ad-hoc basis.

\subsection{Phase four: spatial mapping and distribution of built heritage}

Mapping the sites enabled the spatial analysis of built heritage in Klerksdorp. The distribution pattern of the built heritage sites not only contributed to the formulation of spatial proposals for development, but also created the opportunity to consider these sites on a broader scale and in an integrated manner. Collectively the distribution, prioritisation and spatial analysis culminated in four important findings in terms of spatial planning for integration (Figure 2): i) the location of heritages in the Central Business District are fragmented. These buildings are preserved as isolated objects with no relation to their broader context; ii) structures such as the oldest water reservoir, Palmietspruit bridge (built in 1897 when the railway was extended to Klerksdorp) and the Old Cemetery located outside the town are almost inaccessible, making access, maintenance and integrating these sites proactively in urban development difficult; iii) the changing demographic composition of existing areas, such as Pienaarsdorp that contains numerous examples of historical houses, may present too large a cost to conserve the area as a whole as it has already been transformed into an area that shows signs of urban decay; and iv) heritage resources such as the Old Town heritage cluster, the Streetscape of three historical residences in Viljoen Street in Pienaarsdorp, and the CBD cluster around the Municipal Buildings and Gardens can be spatially clustered due to intergroup proximity.

Old Town Heritage Cluster: The large concentration of heritage sites in Hendrik Potgieter Street and Convent Avenue forms a heritage group or cluster. A heritage cluster provides an opportunity for the conservation of some of the historical buildings and characteristics of the broader area. Hendrik Potgieter Street and Convent Avenue are spatially segregated by the national route (N12) which poses certain challenges in terms of how this area can be managed as a unit. The recognition of this area as a unit is supported by the fact that Hendrik Potgieter Street was indicated as a very important heritage resource in Klerksdorp.

CBD Heritage Cluster: Although heritage sites in the $\mathrm{CBD}$ are scattered to a large extent, the centre of the CBD contains the Municipal Buildings and Gardens 
that are concentrated. This forms an important landmark and focal point in the CBD.

Viljoen Street Streetscape: Viljoen Street is part of a residential area that is transforming from residential to an area with mixed uses. Although numerous examples of Victorian houses are located here, the visual quality of the larger area does not necessarily lend itself to be preserved or rehabilitated as a whole. A specific row of houses in the street was identified as a well-kept example of the streetscape characteristics and it was proposed that this area be conserved as a historical streetscape. However, it will probably remain an isolated heritage if considered against the future development of Klerksdorp and a challenge in terms of maintenance and revitalisation costs of Pienaarsdorp.

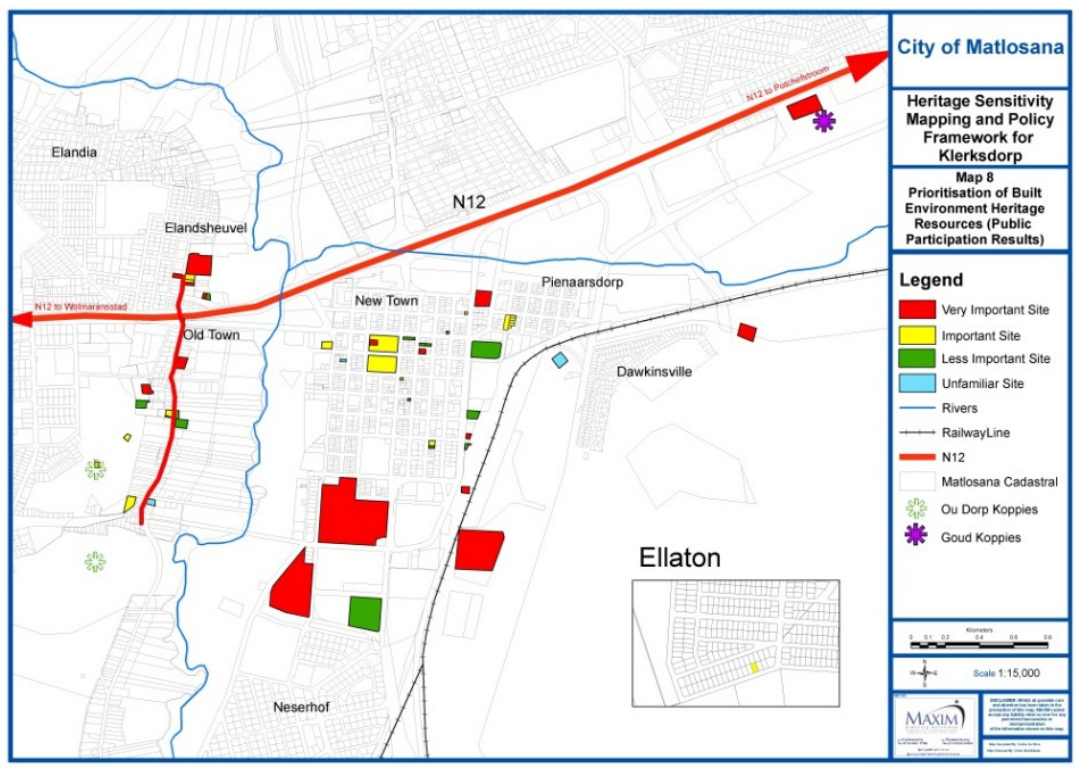

Figure 2: $\quad$ Spatial mapping of built heritage in Klerksdorp.

\section{Proposals for integration}

\subsection{A three-tier framework}

Based on the integrated findings, a three-tier framework is proposed for integrating urban conservation and urban development in the study area (Table 1). The three levels include: i) local spatial planning policies such as the Spatial Development Framework (SDF) and Land Use Management Scheme (LUMS); ii) procedural integration of various municipal departments as well as the proactive inclusion of the public by means of a heritage board and iii) physical/spatial integration through an urban design framework. Within these levels various instruments proposed to implement the framework. 
Table 1: Three-tier framework for integration.

\begin{tabular}{|c|c|c|}
\hline $\begin{array}{l}\text { Level of } \\
\text { integration: }\end{array}$ & Instrument: & Proposal for implementation: \\
\hline \multirow{3}{*}{ Policy/legislation } & $\begin{array}{l}\text { Local development } \\
\text { policies: }\end{array}$ & \multirow{2}{*}{$\begin{array}{l}\text { Earmark of the following: } \\
\text { Heritage Management Zones; } \\
\text { Heritage Sensitivity Zones; } \\
\text { Special redevelopment sites }\end{array}$} \\
\hline & $\begin{array}{l}\text { (i) Spatial Development } \\
\text { Framework (SDF) }\end{array}$ & \\
\hline & $\begin{array}{l}\text { (ii) Land Use Management } \\
\text { System (LUMS) }\end{array}$ & $\begin{array}{l}\text { Inclusion of the following as annexure: } \\
\text { Heritage inventory list }\end{array}$ \\
\hline \multirow[t]{2}{*}{ Procedural } & $\begin{array}{l}\text { (i) Municipal departments } \\
\text { (internal) }\end{array}$ & $\begin{array}{l}\text { Alignment between the following } \\
\text { sections: } \\
\text { Town Planning; } \\
\text { Building Control; } \\
\text { The Museum; } \\
\text { Community services; } \\
\text { Local Economic Development }\end{array}$ \\
\hline & $\begin{array}{l}\text { (ii) Heritage board } \\
\text { (external) }\end{array}$ & $\begin{array}{l}\text { Establishment of a committee of } \\
\text { citizen representatives }\end{array}$ \\
\hline \multirow{2}{*}{ Physical/spatial } & (i) Urban design framework & $\begin{array}{l}\text { Visual links; } \\
\text { Functional and visual upgrade of } \\
\text { surrounding public spaces }\end{array}$ \\
\hline & (ii) Branding & $\begin{array}{l}\text { Exposure of heritage zones, sites } \\
\text { and/or structures on main corridors } \\
\text { e.g. advertising }\end{array}$ \\
\hline
\end{tabular}

\subsection{Instruments for implementation}

Local development policies: The main instruments for implementing the integration through policy and legislation include the Spatial Development Framework and Land Use Management System. The Land Use Management System is a policy that regulates local development in terms of the location and distribution of land uses in such a way that development is executed in an orderly manner. This can be operationalised by adding a list of heritage sites as an annexure to the official policy in order to proactively alert government officials to any potential conflict between development and conservation issues. Another proposal in terms of planning policy is to include special 'heritage management zones' in forward planning by incorporating the identified clusters in the Spatial Development Framework of Klerksdorp, the official policy that guides strategic growth within the municipal boundaries. Detail proposals suggested here include that the Old Town cluster be formally and proactively integrated into future development as the Old Town Heritage Management Zone, while the Viljoen Street residence cluster and CBD Municipal Cluster are proposed to be earmarked as 'Heritage Sensitivity Zones'. Detailed precinct plans should be developed for all of these in order to integrate it in revitalisation strategies of Klerksdorp. Lastly, specific heritage sites/structures e.g. the old reservoir, situated on the Oudorp Koppie ('Old Town Hill') can also be identified as special redevelopment opportunities in order to create investment opportunities for developers. 
Municipal departments (internal) and a heritage borad (external): Alignment between the different departments/sections of the municipality is crucial in the management of heritage sites. The key departments/sections of the municipality that play a role in the management of the heritage resources include: i) the Town Planning Section (responsible for land use management); ii) the Building Control Section (responsible for building plans, conversions, demolitions, renovating and building inspections); iii) the Museum Section (primarily responsible for the cultural heritage resources and history of the municipality); iv) Community Services (maintenance of public places); and v) the Local Economic Development Department (responsible for the promotion of cultural heritage resources for tourism development).

We propose that a system be devised to ensure that all relevant departments are properly consulted prior to any land use change approvals, building plans, demolitions, conversions and infrastructure development that may impact on existing and proposed heritage resources.

A further proposal entails that a body such as a heritage board (committee) be established to ensure active participation in partnership with the municipality. Such a body can play an important role in the identification, assessment, recording and management of heritage resources in cooperation with the municipality. In this way continuous involvement and opportunities for the public to be actively involved in urban conservation can be created.

Spatial integration through an urban design framework and city branding: Spatial integration of the existing fragmented nature of a large percentage of the built heritage can be enhanced by an urban design framework that is dedicated to create functional and visual linkages between heritage sites/structures. However, interventions such as upgrading public spaces surrounding these sites should form part of the framework.

Branding is suggested to create and strengthen existing awareness of heritage sites, as the 55 identified built heritage sites are currently not very visible to tourists. It was proposed that the local heritage of Klerksdorp be visually branded on the N12 Treasure Corridor running through the study area, especially at the transition zone between the Old Town and Convent Avenue over the N12. The detailed nature of the visual design of the branding should form part of the proposed Old Town precinct plan.

Finally, we propose that the results of this research should be communicated to the South African Heritage Resources Agency's provincial body in order to inform them of the initiatives on the local front. All owners of heritage sites should be officially notified of the results of the research to create awareness that these sites will be regarded as sensitive in terms of any development. Also, the local authority should be responsible for the protection and management of these sites, as well as the implementation of the proposals.

While the above form broad proposals for integrating urban conservation and urban development, the detail actions for implementation needs to be refined as this falls outside the scope of this paper. 


\section{Conclusions}

This paper suggests a shift in how urban conservation is viewed in the sense that it should move from preserving heritage resources as isolated objects towards a more integrated view where heritage resources are proactively integrated into the contemporary uses and future development of cities to ensure the continued existence of these assets. It emphasises the proactive role of urban planning in combining the past with contemporary use and possible levels of integrating urban conservation and urban development. A balanced approach to integration is suggested that implies integrating built heritage into the current urban milieu so as to fulfil current needs (e.g. social, cultural and economic needs) $[5,8,19]$, without actually destroying or indelibly altering it in a negative manner.

\section{References}

[1] World urbanisation prospects: the 2001 revision; United Nations, Department of Economic and Social Affairs/Population Division, Online. http://esa.un.org/unup/

[2] Beall, J. \& Fox, S., Cities and development, Routledge: London, pp. 27-67, 2009.

[3] Cohen, N., Urban planning conservation and preservation, New York: McGraw-Hill, pp. 9-11, 2001.

[4] Benhamou, F., Heritage (Chapter 32). A handbook of cultural economics, ed. R. Towse, Edward Elgar Publishing Limited: Cheltenham, UK, pp. 255262, 2003.

[5] Nasser, N., Planning for urban heritage places: reconciling conservation, tourism, and sustainable development. Journal of Planning Literature, 17(4), pp. 467-479, 2003.

[6] Ruijgrok, E.C.M., The three economic values of cultural heritage: a case study in the Netherlands, Journal of Cultural Heritage, 7, pp. 206-213, 2006.

[7] Amit-Cohen, I., Synergy between urban planning, conservation of the culture built heritage and functional changes in the old urban center - the case of Tel Aviv. Land Use Policy, 22, pp. 291-300, 2004.

[8] Horayangkura, V., In search of sustainable paradigms for conservation and development based on underlying convergent/divergent conceptions. Journal of Architectural/Planning Research and Studies, 6(3), pp. 3-21, 2009.

[9] Ashworth, G.J., Conservation as Preservation or as Heritage: two paradigms and two answers (Chapter 19). Designing cities: critical readings in urban design, ed. A.R. Cuthbert, Blackwell Publishing: Malden, MA, pp. 243-253, 2003.

[10] Ceaseless time; Karácsony, A., Elte University, Faculty of Law, Budapest, online. http://ajkteszt.elte.hu/file/KaracsonyAndras-Caeseless.pdf

[11] East vs. West; A. Bivikova \& V. Kotelnikov, V., Online. http://www.1000ventures.com/business_guide/crosscuttings/cultures_eastwest-phylosophy.html 
[12] Mbiti, J.S., African Religions and Philosophy, Heinemann: London, pp. 1288, 1969.

[13] Harvey, D., The Condition of Postmodernity, Basil Blackwell Ltd: Cambridge, MA, pp. 1-368, 1989.

[14] Jixiang, S., Dialectical speculations on the scientific and technological aspects of cultural heritage protection. Museum International, 60(1-2), pp. 237-238, 2008.

[15] Ashworth, G.J., Graham, B. \& Tunbridge, J.E., Pluralising pasts: Heritage, identity and place in multicultural societies, London: Pluto Press, pp. 1-236, 2007.

[16] Peckham, R.S., Rethinking heritage: cultures and politics in Europe, I.B. Tauris: London, pp. 1-214, 2003.

[17] Ashworth, G.J. \& Tunbridge, J.E., Old cities, new pasts: Heritage planning in selected cities of Central Europe. Geo Journal, 49, pp. 105-116, 1999.

[18] Lowenthal, D., The heritage crusade and the spoils of history, Cambridge University Press: Cambridge, UK, pp. 1-250, 1998.

[19] Heylighen, A., Inclusive built heritage as a matter of concern: a field experiment (Chapter 21). Designing inclusive systems: Designing inclusion for real-world applications, eds. P. Langdo, J. Clarkson, P. Robinson, J. Lazar, \& A. Heylighen, A., Springer: London, pp. 207-216, 2012.

[20] Mabin, A. \& Smit, D., Reconstructing South Africa's cities? The making of urban planning 1900-2000. Planning Perspectives, 12(2), pp. 193-223, 1997.

[21] Cultural heritage and the law, ICCROM, Online. http://www.iccrom.org /pdf/ICCROM_ICS08_CulturalHeritageandLaw_en.pdf

[22] The cultural heritage of democratic South Africa: An overview, H.C Bredekamp, Online. http://www.dissanet.com/ifla/pdf/LIASA\%2001\%20 Bredekamp.pdf

[23] South Africa, National Heritage Resources Act No. 25 of 1999, Government Press: Pretoria, pp. 1-45, 1999.

[24] South Africa, National Environmental Management Act No. 107 of 1999, Government Press: Pretoria, pp. 1-72, 1998.

[25] South Africa, Wold Heritage Convention Act No. 49 of 1999, Government Press: Pretoria, pp. 1-28, 1999.

[26] What is planning? American Planning Association, Online. http://www.planning.org/aboutplanning/whatisplanning.htm

[27] North West Provincial Government. North West Spatial Development Framework, Government Printer: Klerksdorp, pp. 9-14, 2005.

[28] Guest, H.H., Voortrekkerdorp, Klerksdorp Record (Pty.) Ltd.: Klerksdorp, p. 27, 1945.

[29] Creswell, J.W., Qualitative inquiry and research design: Choosing among five approaches, Sage: Thousand Oaks, CA, pp. 1-416, 1998.

[30] Babbie, E. \& Mouton, J. The practice of social research, Oxford University Press: Oxford, pp. 1-498, 2001. 